\title{
Article \\ Genomic Characterization and Therapeutic Targeting of HPV Undetected Cervical Carcinomas
}

\author{
Fiona J. Ruiz ${ }^{1,2}$, Aishwarya Sundaresan ${ }^{3}$, Jin Zhang ${ }^{2,4,5}$, Chandra S. Pedamallu ${ }^{6} \mathbb{D}_{\text {, Mari K. Halle }}{ }^{6,7,8} \mathbb{D}^{\text {, }}$ \\ Vinodh Srinivasasainagendra ${ }^{3}$, Jianqing Zhang 6,9, Naoshad Muhammad ${ }^{2}$, Jennifer Stanley ${ }^{2,5}$, \\ Stephanie Markovina ${ }^{2,5}$, Hemant K. Tiwari ${ }^{3}$, Perry W. Grigsby ${ }^{2,5}$, Camilla Krakstad ${ }^{7,8}$ (D), \\ Julie K. Schwarz ${ }^{1,2,5,10,+}$ and Akinyemi I. Ojesina $6,9,11, *,+$
}

\section{check for} updates

Citation: Ruiz, F.J.; Sundaresan, A.; Zhang, J.; Pedamallu, C.S.; Halle, M.K.; Srinivasasainagendra, V.; Zhang, J.; Muhammad, N.; Stanley, J.; Markovina, S.; et al. Genomic Characterization and Therapeutic Targeting of HPV Undetected Cervical Carcinomas. Cancers 2021, 13, 4551. https://doi.org/10.3390/ cancers 13184551

Academic Editor: Thilo Dörk

Received: 23 July 2021

Accepted: 3 September 2021

Published: 10 September 2021

Publisher's Note: MDPI stays neutral with regard to jurisdictional claims in published maps and institutional affiliations.

Copyright: (c) 2021 by the authors. Licensee MDPI, Basel, Switzerland. This article is an open access article distributed under the terms and conditions of the Creative Commons Attribution (CC BY) license (https:/ / creativecommons.org/licenses/by/ $4.0 /)$.
1 Division of Biological and Biomedical Sciences Molecular Cell Biology, Washington University School of Medicine, St. Louis, MO 63108, USA; fiona@wustl.edu (F.J.R.); jschwarz@wustl.edu (J.K.S.)

2 Department of Radiation Oncology, Washington University School of Medicine, St. Louis, MO 63108, USA; jin.zhang@wustl.edu (J.Z.); nmuhammad@wustl.edu (N.M.); jastanley@wustl.edu (J.S.); smarkovina@wustl.edu (S.M.); pgrigsby@wustl.edu (P.W.G.)

3 Department of Biostatistics, University of Alabama at Birmingham, Birmingham, AL 35294, USA; aish8586@gmail.com (A.S.); vinodh@uab.edu (V.S.); htiwari@uab.edu (H.K.T.)

4 Institute for Informatics, Washington University School of Medicine, St. Louis, MO 63108, USA

5 Alvin J. Siteman Cancer Center, Washington University School of Medicine, St. Louis, MO 63108, USA

6 Department of Epidemiology, University of Alabama at Birmingham, Birmingham, AL 35294, USA; pcs.murali@gmail.com (C.S.P.); mari.halle@uib.no (M.K.H.); jianqing@uab.edu (J.Z.)

7 Department of Obstetrics and Gynaecology, Haukeland University Hospital, 5021 Bergen, Norway; camilla.krakstad@uib.no

8 Centre for Cancer Biomarkers, Department of Clinical Science, University of Bergen, 5020 Bergen, Norway

9 O'Neal Comprehensive Cancer Center, University of Alabama at Birmingham, Birmingham, AL 35294, USA

10 Department of Cell Biology and Physiology, Washington University School of Medicine, St. Louis, MO 63108, USA

11 HudsonAlpha Institute for Biotechnology, Huntsville, AL 35806, USA

* Correspondence: ojesina@uab.edu; Tel.: +1-205-934-7911

+ J. K. Schwarz and A. I. Ojesina are joint senior authors.

Simple Summary: Persistent HPV infection is a known driver of cervical carcinogenesis, but the existence and biological relevance of $\mathrm{HPV}$ undetected $\left(\mathrm{HPV}^{\mathrm{U}}\right)$ cervical cancer has been debated. Here we report the results of detailed molecular classification of $\mathrm{HPV}^{\mathrm{U}}$ cervical cancer, and validate $\mathrm{HPV}^{\mathrm{U}}$ as a biomarker of poor outcomes. We identify that $\mathrm{HPV}^{\mathrm{U}}$ cervical cancer tumors harbor mutations affecting cell cycle progression, and in vitro experiments reveal $\mathrm{HPV}^{\mathrm{U}}$, but not $\mathrm{HPV}^{+}$, cells are sensitive to palbociclib monotherapy. $\mathrm{HPV}^{\mathrm{U}}$ status can be translated into the clinic as a predictive biomarker of poor patient response to standard of care treatments and these patients may benefit from personalized treatment plans. Our results identify palbociclib as a lead candidate as an alternative treatment strategy for $\mathrm{HPV}^{\mathrm{U}}$ cervical cancer patients. We also suggest that primary cervix tumors be routinely tested for HPV prior to treatment to identify patients who will benefit from more aggressive precision-driven therapy.

Abstract: Cervical cancer tumors with undetectable $\mathrm{HPV}\left(\mathrm{HPV}^{\mathrm{U}}\right)$ have been underappreciated in clinical decision making. In this study, two independent $C C$ datasets were used to characterize the largest cohort of $\mathrm{HPV}^{\mathrm{U}}$ tumors to date $\left(\mathrm{HPV}^{\mathrm{U}}=35, \mathrm{HPV}^{+}=430\right)$. Genomic and transcriptome tumor profiles and patient survival outcomes were compared between $\mathrm{HPV}^{+}$and $\mathrm{HPV}^{\mathrm{U}}$ tumors. In vitro analyses were done to determine efficacy of the selective CDK4/6 inhibitor palbociclib on $\mathrm{HPV}^{\mathrm{U}}$ cancer cell lines. Patients with HPV ${ }^{\mathrm{U}} \mathrm{CC}$ tumors had worse progression-free and overall survival outcomes compared to $\mathrm{HPV}^{+}$patients. TP53, ARID1A, PTEN, ARID5B, CTNNB1, CTCF, and CCND1 were identified as significantly mutated genes (SMGs) enriched in $\mathrm{HPV}^{\mathrm{U}}$ tumors, with converging functional roles in cell cycle progression. In vitro $\mathrm{HPV}^{\mathrm{U}}$, but not $\mathrm{HPV}^{+}$, cancer cell lines with wild type $R B 1$ were sensitive to palbociclib monotherapy. These results indicate that HPV ${ }^{\mathrm{U}}$ status can be translated into the clinic as a predictive biomarker of poor patient response to standard of care treatments. We suggest primary cervix tumors be routinely tested for HPV prior to treatment to 
identify patients who will benefit from more aggressive precision-driven therapy. Our results identify palbociclib as a lead candidate as an alternative treatment strategy for $\mathrm{HPV}^{\mathrm{U}} \mathrm{CC}$ patients.

Keywords: HPV; palbociclib; cervix

\section{Introduction}

Cervical cancer (CC) is the fourth leading cause of cancer amongst women worldwide [1]. Persistent human papilloma virus (HPV) infection is causative for at least $90 \%$ of cervical cancers, as well as the majority of vulvar, vaginal, anal, penile, and oropharyngeal cancers [2]. Previously published studies have demonstrated that for both oropharyngeal and cervical cancer, patients with undetectable tumor HPV DNA and RNA have worse overall survival outcomes [3-11]. Based upon these findings, guidelines now require mandatory HPV testing in all newly diagnosed oropharyngeal squamous cell carcinomas [4].

In the context of cervical cancer, HPV screening is recommended for women aged 30-65 in addition to pap smears every 5 years [12]. However, upon cervical cancer diagnosis there are currently no established guidelines for clinical HPV testing of primary cervix tumors. In clinical practice, most cervical cancer cases are assumed to be HPVdriven. However, retrospective studies suggest that $7-11 \%$ of cervical tumors do not have detectable HPV DNA and or RNA, hereafter referred to as HPV undetectable ( $\mathrm{HPV}^{\mathrm{U}}$ ) tumors [7-10,13,14]. The Cancer Genome Atlas (TCGA) analysis of cervix cancer also found that $5 \%$ of cervical tumors were $\mathrm{HPV}^{\mathrm{U}}$ [15].

For patients receiving the standard of care concurrent administration of cisplatin chemotherapy with pelvic irradiation $[7-9,16], \mathrm{HPV}^{\mathrm{U}}$ is an indicator for poor progressionfree and overall survival. Overall failure rates for standard of care chemoradiation are as high as $67 \%$ in some series for patients with $\mathrm{HPV}^{\mathrm{U}}$ tumors [8]. Identifying $\mathrm{HPV}^{\mathrm{U}} \mathrm{CC}$ before initiating treatment has the potential to improve outcomes by allowing for personalized treatment planning.

In our previous work, we reported on the landscape of genomic alterations in cervical cancer [17], but the sample sizes were inadequate for identifying $\mathrm{HPV}^{\mathrm{U}}$ associated genomic alterations. To date there have been no comprehensive studies integrating the investigation of genomic characteristics and therapeutic options for $\mathrm{HPV}^{\mathrm{U}} \mathrm{CC}$ compared to $\mathrm{HPV}^{+}$tumors. In this study we aimed to (1) characterize the genomic landscape and transcriptome of $\mathrm{HPV}^{\mathrm{U}}$ compared to $\mathrm{HPV}^{+} \mathrm{CC}$ tumors; and (2) investigate clinically actionable targets that are unique to $\mathrm{HPV}^{\mathrm{U}} \mathrm{CC}$ tumors and can be exploited for therapeutic intervention.

\section{Materials and Methods}

\subsection{Patient Cohorts}

Genomic analyses were performed on 2 sets of data (Figure 1A). For the first set, we analyzed whole exome, copy number and RNA sequencing data archived in dbGaP which were originally derived from two published sources: Ojesina et al. [17], and the Cancer Genome Atlas Network (TCGA) [15] (accession numbers phs000600.v1.p1 and phs000178.v11.p8, respectively). The current investigations focused on the prospectively followed Norwegian (NOR) subset of the Ojesina et al. project. The 379 cervical tumors in the "NOR-TCGA set") included 299 squamous cell carcinomas, 47 adenocarcinomas and 34 other tumors of varying histologies (Table S1), The WUSM cohort included 72 squamous cell carcinomas, 9 adenocarcinomas, and 5 other tumors of varying histologies (Table S1), which were subjected to a targeted exome sequencing panel with 237 genes prioritized based on previous genomics studies [17,18] (Table S2). 

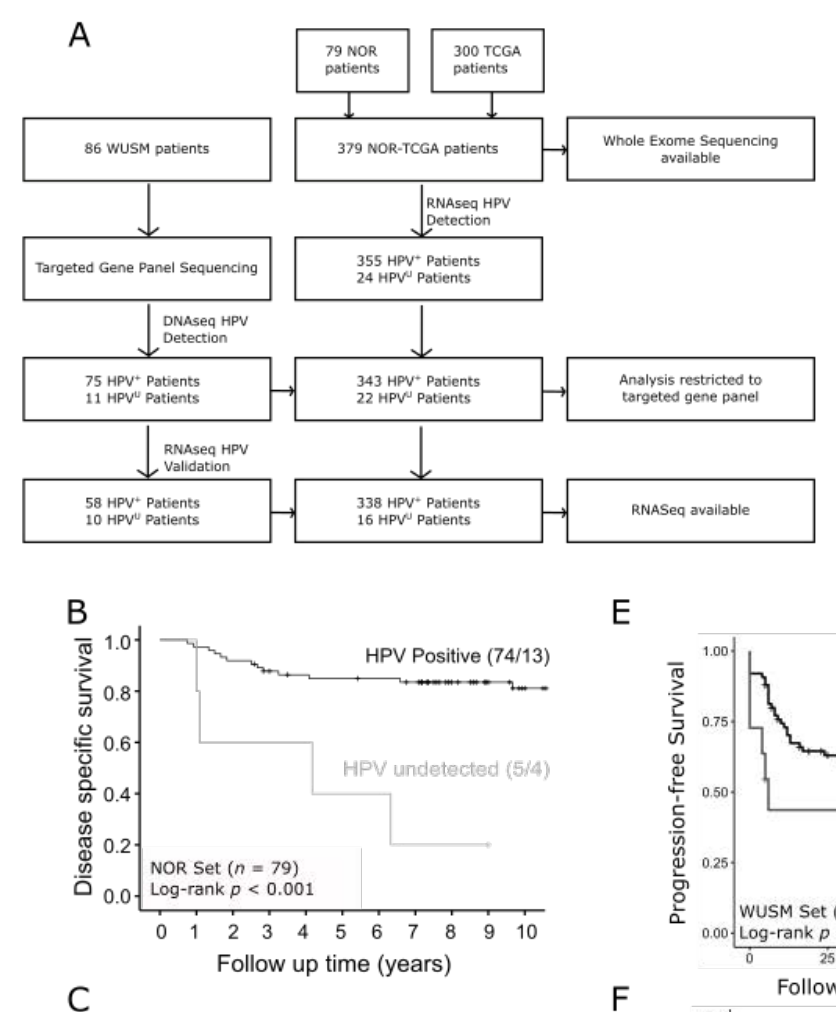

E

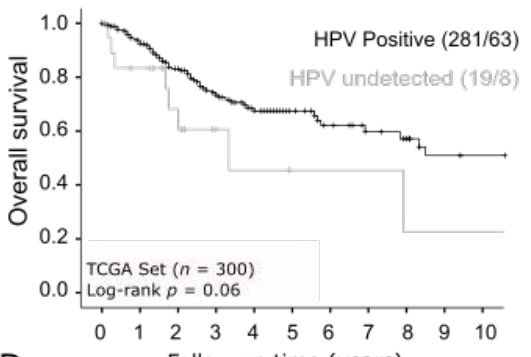

$\mathrm{F}$
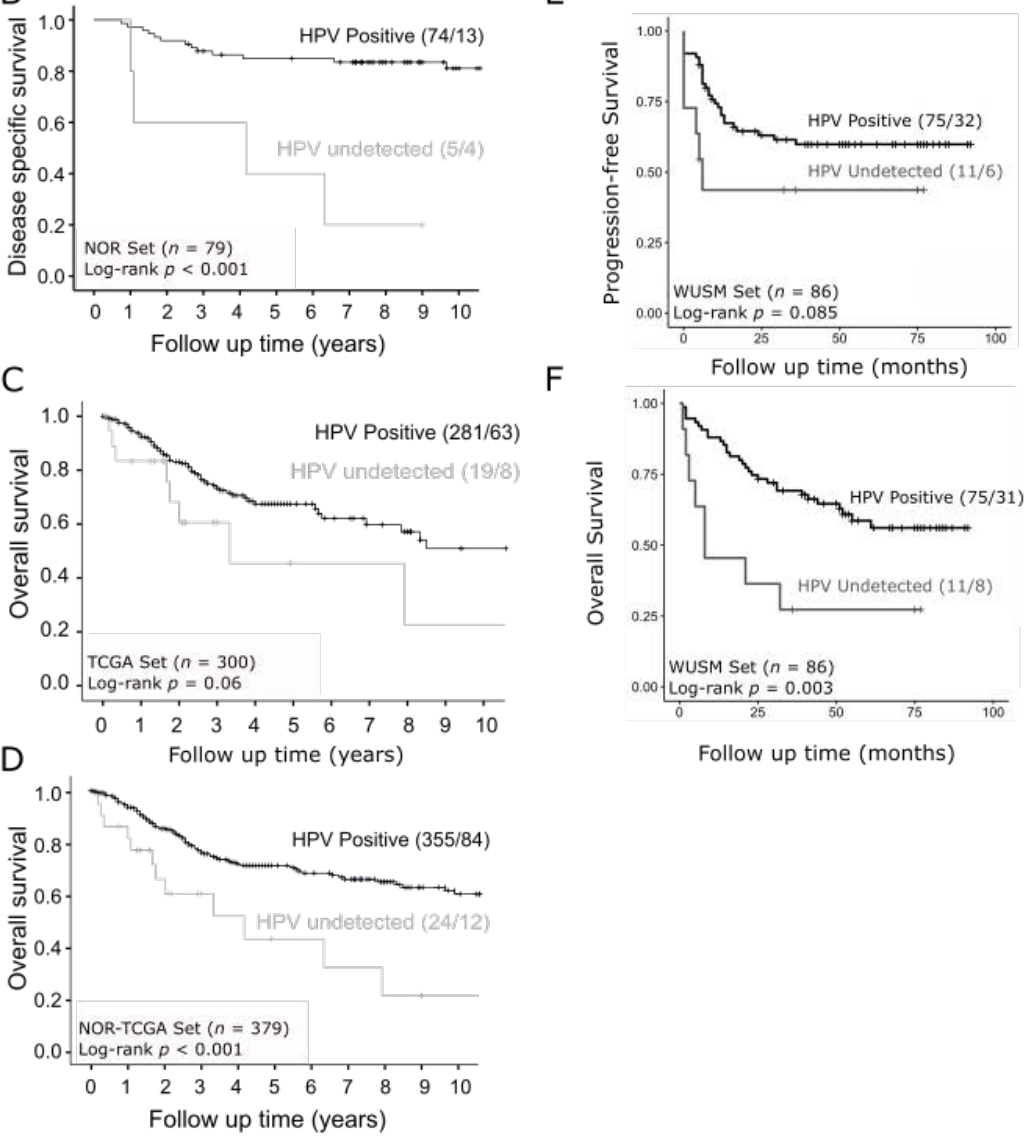

Figure 1. Patient cohorts and survival outcomes in $\mathrm{HPV}^{\mathrm{U}}$ cervical cancer. (A) CONSORT diagram depicting patient samples from NOR-TCGA and WUSM study cohorts and the number of patients at each step of the analysis. (B-E) shows Kaplan-Meier survival analysis for HPV ${ }^{\mathrm{U}}$ (grey) and $\mathrm{HPV}^{+}$(black) patients, using log-rank test to test for significance. (B) NOR patients disease specific survival, (C) TCGA cervix overall survival and (D) overall survival in the combined NOR-TCGA set, (E) progression-free survival in WUSM cohort, (F) overall survival in WUSM cohort.

\subsection{Defining Tumors with Undetectable $H P V\left(H P V^{U}\right)$}

The CESC TCGA standard of HPV detection of at least $1 \mathrm{HPV}$ read per million human reads was employed to identify patients with $\mathrm{HPV}^{+}$positive and $\mathrm{HPV}^{\mathrm{U}}$ tumors [15]. In the NOR-TCGA set, 24 patient samples met this definition based on PathSeq analyses of RNA sequencing (RNAseq) data [19]. The WUSM cohort defined HPV status using DNA sequencing and validated with RNAseq. Specifically, any sample with no HPV reads detected were defined as $\mathrm{HPV}^{\mathrm{U}}(n=11)$. These $\mathrm{HPV}^{\mathrm{U}}$ samples with corresponding 
RNAseq data $(n=10)$ were then validated by aligning to reference genomes for high-risk HPV 16, 18, 31, 33, 45, 52, 56, 58, and 59. $\mathrm{HPV}^{\mathrm{U}}$ was defined as any sample with less than $1 \mathrm{HPV}$ read in 1 million human reads. All 10 WUSM samples called as HPV ${ }^{\mathrm{U}}$ by DNA probes were also negative using the RNAseq cutoffs.

\subsection{Genomic DNA Analyses}

Mutect2.0 and MutSig2CV [20,21] analyses were performed on the whole-exome sequencing for the $24 \mathrm{HPV}^{\mathrm{U}}$ and $355 \mathrm{HPV}^{+}$tumors in the NOR-TCGA set and significantly mutated genes (SMGs) were identified using a false discovery rate (FDR) of 0.1. SMGs were also analyzed for either co-occurrence or mutual exclusivity of mutations with other SMGs. GISTIC2.0 [22] analyses were also performed on copy number SNP data for the $24 \mathrm{HPV}^{\mathrm{U}}$ tumors using FDR $\leq 0.25$. Targeted gene exome sequencing for 237 pan cancer associated genes was performed on 86 tumor-blood pairs from the WUSM cohort (Table S2). Combined analysis of NOR-TCGA and WUSM cohort samples were restricted to the 211 genes with mutations in both the whole exome and targeted gene lists.

\subsection{RNAseq Analysis}

RNAseq analyses were performed for 354 NOR-TCGA (73 Norwegian, 281 TCGA) and 68 WUSM cohort tumors independently and used as test and validation datasets, respectively, to assess transcript expression differences between $\mathrm{HPV}^{\mathrm{U}}$ and $\mathrm{HPV}^{+}$cervical cancer tumors. Mann-Whitney/Wilcoxon tests were used to identify SMGs with differential transcript expression $(p<0.05)$. Additionally, differential expression (DE) analysis was performed using $R$ version 3.5.2 and DESeq2 package on the $10 \mathrm{HPV}^{\mathrm{U}}$ and $58 \mathrm{HPV}^{+}$ tumors from the WUSM cohort. DE genes used for subsequent GSEA pathway analysis had a $\log 2$ fold change $>1$ or $<-1$ and $p$-adj $<0.01$. Pathway analysis was restricted to hallmark gene sets that had at least $10 \%$ of the pathway contributed from DE genes and an FDR $<0.01$.

\subsection{Cell Line Selection}

Wild-type (WT) RB1 is necessary for palbociclib to be effective [23]. However, the COSMIC cell line database (accessed on November 2019) revealed that the prototypical $\mathrm{HPV}^{\mathrm{U}}$ cervical cancer cell lines, HT3 and C33A harbor mutant RB1 (Table S4). Therefore, the HPV ${ }^{\mathrm{U}}$ Fadu and HPV 16 positive SCC-47 and SCC-154 HNSCC cell lines were used to evaluate efficacy of palbociclib treatment in $\mathrm{HPV}^{+}$and $\mathrm{HPV}^{\mathrm{U}}$ cancer cell lines. Fadu cells were obtained from the American Type Culture collection (ATCC), SCC-47 from Millipore, and SCC-154 from University of Pittsburgh and maintained in IMDM media (Life Technologies, Carlsbad, CA, USA) with 10\% heat inactivated FBS and incubated at $37^{\circ} \mathrm{C}$ in $5 \% \mathrm{CO}_{2}$. Mycoplasma testing was performed periodically to verify no infection. Experiments were performed on cell lines under passage 30. Palbociclib was dissolved in $0.01 \%$ of dimethyl sulfoxide (DMSO). All three HNSCC cell lines had WT RB1 genotypes, while Fadu also had overexpression of cyclin D1 as assessed by Western blot using anticyclin D1 (92G2) (Cell Signaling Technology, Danvers, MA, USA).

\subsection{HPV U Cell Line Sensitivity to Palbociclib}

Cells were treated with increasing doses of single agent palbociclib (PZ0383) (SigmaAldrich, St Louis, MO, USA). Treated cell viability was normalized to untreated control cells. Combination palbociclib and radiation treatment was also evaluated, cells were treated with palbociclib $1 \mathrm{hr}$ prior to single-fraction 2 or $4 \mathrm{~Gy}$ radiation treatment. Five days after treatment cell viability was quantified using alamarBlue cell viability reagent according to the manufacturer's protocol (Thermo Fisher Scientific, Waltham, MA, USA).

\subsection{Palbociclib Induced G1 Arrest and Proliferation Attenuation}

G1 cell cycle arrest was evaluated by treating cells with vehicle $(0.01 \%$ DMSO) or $0.25 \mu \mathrm{M}$ palbociclib and harvesting them 24 and $48 \mathrm{~h}$ after treatment. Cells were stained 
with propidium iodide and run for flow cytometry on the MACSQuant analyzer (Miltenyl Biotec, Bergisch Gladbach, Germany). Attenuation in proliferation was evaluated by treating cells with either vehicle or $0.25 \mu \mathrm{M}$ palbociclib and counting cells at 6-, 9-, and 12-days post-treatment. A representative day 12 plate was crystal violet stained and visualized.

\subsection{Statistics}

The Kaplan-Meier method and log rank test were used to determine differences in progression-free and overall survival, using the $\mathrm{R}$ version 3.5.2 packages survminer and survival. Fisher exact test was used to identify SMGs in the NOR-TCGA and WUSM cohorts. Mann-Whitney/Wilcoxon tests were used to identify SMGs with differential transcript expression. The Wilcoxon signed-rank test and student t-tests were used for in vitro experiments. $P$ less than 0.05 was set as the threshold for significance of all study outcomes.

\section{Results}

\subsection{Survival Outcomes Are Poor for Patients with HPV U Cervical Tumors}

The CONSORT diagram depicting patient/sample distributions are shown in Figure 1A. Patients enrolled in the Norwegian cohort were mostly stage Ib-II and treated by standard of care surgical resection. $\mathrm{HPV}^{\mathrm{U}}$ patients from this cohort had worse disease-specific survival outcomes compared to $\mathrm{HPV}^{+}$patients $(p<0.001)$ (Figure 1B). The patients enrolled in the TCGA cervix study were not uniformly treated and clinical follow up was not a requirement, despite this we see a similar trend of patients with $\mathrm{HPV}^{\mathrm{U}}$ cervical tumors having worse overall survival compared to $\mathrm{HPV}^{+}$patients $(p=0.06)$ (Figure 1C). Survival analyses for the combined NOR-TCGA set confirm that patients with HPV ${ }^{\mathrm{U}}$ cervix tumors have worse overall survival outcomes compared to those with $\mathrm{HPV}^{+}$cervical cancer $(p=0.001)$ (Figure 1D). Patients from the WUSM cohort had advanced staged disease and were uniformly treated with the standard of care curative intent radiation treatment and concurrent platinum-based chemotherapy (CRT). Similar to other studies, WUSM cohort patients with $\mathrm{HPV}^{\mathrm{U}}$ cervical tumors had worse progression free survival and higher mortality rates compared to patients with $\mathrm{HPV}^{+}$tumors (Figure 1E,F). Furthermore, across all cohorts $\mathrm{HPV}^{\mathrm{U}}$ cervical tumors were more likely to have non-squamous histology and occur with higher frequency in patients $\geq 50$ years old compared with $\mathrm{HPV}^{+}$tumors (Table S1).

\subsection{Discovery of Significantly Mutated Genes Defines a Distinct Biology in HPVU Tumors}

Mutect2.0 analyses of the $24 \mathrm{HPV}^{\mathrm{U}}$ tumors in the NOR-TCGA set revealed a total of 10,182 somatic mutations, including 6314 missense, 586 nonsense, 2232 silent, 266 splice site mutations, as well as 480 deletions, 90 insertions, and 214 miscellaneous mutations. The aggregate non-silent mutation rate was 3.1 per Mb. MutSig2CV analyses revealed TP53, PTEN, KRAS, and ARID1A as significantly mutated genes (SMGs) at the false discovery rate of $\mathrm{q}<0.1$. Recurrent mutations in these genes occurred in 50\%, 29\%, 21\%, and 33\% respectively (Table S3).

In order to identify additional putative SMGs associated with $\mathrm{HPV}^{\mathrm{U}}$ tumors, we compared the relative frequencies of mutations in $\mathrm{HPV}^{\mathrm{U}}$ versus $\mathrm{HPV}^{+}$cervical tumors, using two complementary datasets (the NOR-TCGA set alone, and a combined NORTCGA/WUSM set). For the first set, the comparison of relative mutational frequency was focused on the 1569 genes which met at least one of the following criteria: (i) MutSig2CV $p$ value $<0.1$ in either $\mathrm{HPV}^{\mathrm{U}}$ or $\mathrm{HPV}^{+}$tumors; and (ii) any gene with $>1$ mutation in $\mathrm{HPV}^{\mathrm{U}}$ tumors and zero mutations in $\mathrm{HPV}^{+}$tumors. These criteria allowed for the investigation of genes which would otherwise be deemed non-significant in MutSig2CV analyses due to the small sample size, with a stringent false discovery rate $<0.05$ following Fisher's exact test and Benjamini-Hochberg correction. The genes with higher frequencies of somatic mutations in $\mathrm{HPV}^{\mathrm{U}}$ compared with $\mathrm{HPV}^{+}$cervical tumors include TP53, RICTOR, ARID1A, ARHGEF2, ZNF331, CTNNB1, KIAA3012, and MC5R (Table 1). In the second phase, we 
combined NOR-TCGA and WUSM samples order to increase the sample size for HPV samples. Comparison of relative mutational frequencies in the combined dataset was focused on the 211 genes with mutations in both the whole exome and targeted gene lists. The genes with significantly higher frequencies in $\mathrm{HPV}^{\mathrm{U}}$ tumors (Fisher's exact test with FDR 0.05), were TP53, ARID5B, ARID1A, PTEN, CTNNB1, CTCF, and CCND1 (Table 1). CCND1 had recurrent P287T mutations.

Table 1. Significantly mutated genes (SMGs) enriched in $\mathrm{HPV}^{\mathrm{U}}$ tumors.

\begin{tabular}{|c|c|c|c|c|}
\hline \multicolumn{5}{|c|}{ Whole-Exome Analysis: 1569 Genes } \\
\hline NOR-TCGA & Gene & $\begin{array}{l}\text { Relative Frequency of HPV } \\
\text { Undetected Tumors with Mutation (\%) } \\
\qquad(n=24)\end{array}$ & $\begin{array}{c}\text { Relative Frequency of HPV } \\
\text { Positive Tumors with Mutation (\%) } \\
(n=355)\end{array}$ & FDR $p$-Value \\
\hline & TP53 & 50.0 & 3.1 & $2.65 \times 10^{-7}$ \\
\hline & ARID1A & 33.3 & 5.4 & $2.05 \times 10^{-2}$ \\
\hline & RICTOR & 20.8 & 0.6 & $1.01 \times 10^{-2}$ \\
\hline & ARHGEF2 & 20.8 & 1.4 & $3.05 \times 10^{-2}$ \\
\hline & ZNF331 & 16.7 & 0.3 & $3.14 \times 10^{-2}$ \\
\hline & CTNNB1 & 16.7 & 0.3 & $3.14 \times 10^{-2}$ \\
\hline & KIAA1012 & 16.7 & 0.3 & $3.14 \times 10^{-2}$ \\
\hline & MC5R & 12.5 & 0 & $4.41 \times 10^{-2}$ \\
\hline \multicolumn{5}{|c|}{ Combined Targeted Gene Panel and Whole-Exome Analysis: 211 Genes } \\
\hline $\begin{array}{l}\text { NOR-TCGA } \\
\text { + WUSM }\end{array}$ & Gene & $\begin{array}{l}\text { Relative Frequency of HPV } \\
\text { Undetected Tumors with Mutation (\%) } \\
\qquad(n=33)\end{array}$ & $\begin{array}{l}\text { Relative Frequency of HPV } \\
\text { Positive Tumors with Mutation (\%) } \\
(n=418)\end{array}$ & FDR $p$-Value \\
\hline & TP53 & 45.45 & 3.83 & $8.82 \times 10^{-9}$ \\
\hline & ARID1A & 33.33 & 6.22 & $9.61 \times 10^{-4}$ \\
\hline & PTEN & 30.3 & 5.74 & $1.75 \times 10^{-3}$ \\
\hline & ARID5B & 21.21 & 0.72 & $6.43 \times 10^{-5}$ \\
\hline & CTNNB1 & 15.15 & 0.96 & $6.69 \times 10^{-3}$ \\
\hline & CTCF & 15.15 & 1.44 & $1.84 \times 10^{-2}$ \\
\hline & CCND1 & 9.09 & 0.24 & $4.11 \times 10^{-2}$ \\
\hline
\end{tabular}

Top: Mutational frequencies of genes with whole exome MutSig2CV $p$ value $<0.1$, or genes with $>1$ mutation in $\mathrm{HPV}^{\mathrm{U}}$ tumors and 0 mutations in $\mathrm{HPV}^{+}$tumors (1569 genes in all) were compared between $\mathrm{HPV}^{\mathrm{U}}$ and $\mathrm{HPV}^{+}$tumors. Bottom: Mutational frequencies of the 211 genes with mutations observed in both the whole exome and targeted gene lists were compared between $\mathrm{HPV}^{\mathrm{U}}$ and $\mathrm{HPV}^{+}$tumors.

GISTIC2.0 analysis of somatic copy number alterations (SCNA; threshold of $q<0.25$ ) revealed 6 significant focal amplifications in the following cytobands (listed in genomic order with some genes in the peaks in parentheses): 3q26.31 (GHSR, FNDC3B), 7p15.3 (IGF2BP3, IL6), 8p11.22 (FGRFR1, TACC1), 11q13.3 (CCDN1, FGF3, FGF4), 11q22.1 (TRPC6), $17 \mathrm{q} 12$ (ERBB2), 19q12 (CCNE1), and Xq21.33 (no gene in the peak but close to FAM133A) (S4). In addition, six significant focal deletion peaks were identified in cytobands 3p14.2 (FHIT), 4q35.2 (FAT1, CASP3), 5q12.3 (PPWD1, RAD17, PIK3R1), 15q22 (RNF111, CCNB2), 19p12 (RPSAP58), and 22q13.32 (PANX2, NCAPH2) (Figure S1).

Unsupervised hierarchical clustering of a combined set of SMGs and SCNAs yielded a striking segregation of $\mathrm{HPV}^{\mathrm{U}}$ tumors into two unique subsets: an SMG-rich subset with tumors harboring most of the SMGs except for TP53, and an SCNA-rich subset which harbored most of the SCNAs and displayed strong overlap with TP53 mutation (Figures 2 and S2). On the level of individual SMGs, ZNF331 mutations co-occurred with CTCF $(p=0.007623)$ and ARID1A $(p=0.00659)$ mutations, and KIAA1012 mutations cooccurred with MC5R mutations ( $p=0.000198)$ (Table S3). TP53 mutations found in HPV ${ }^{\mathrm{U}}$ 
tumors were mutually exclusive with ARID1A $(p=0.027)$, ZNF331 $(p=0.0466)$, and NCAPH2 ( $p=0.0466)$ mutations (Table S3).
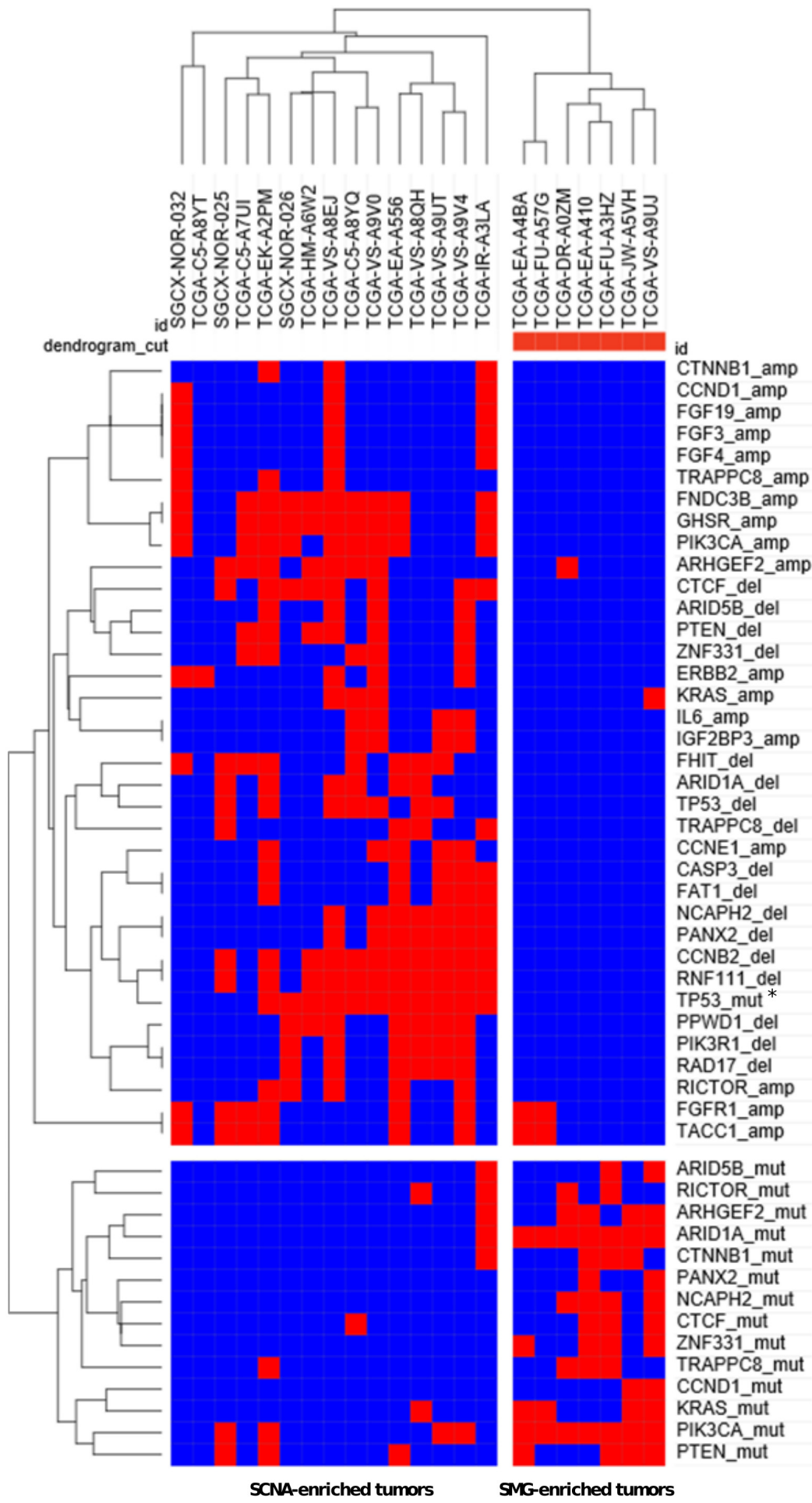

Figure 2. Hierarchical clustering SMGs and SCNAs. A full complement of mutations and SCNAs affecting SMGs and genes in copy number peaks were summarized a matrix and subjected to hierarchical clustering. Red and blue squares represent presence and absence, respectively, of mutation or alteration. Nomenclature: genename_amp, genename_del, and genename_mut represent amplifications, deletions and mutations involving each respective gene. ${ }^{*} p<0.05$. 


\subsection{Significantly Mutated Genes Disrupt Cell Cycle Regulation in HPV ${ }^{U}$ Cervical Cancer}

The SMGs ARHGEF2, CCND1, and CTNNB1 all had higher transcript expression in $\mathrm{HPV}^{\mathrm{U}}$ tumors from both the NOR-TCGA and WUSM patient cohorts (Figures $3 \mathrm{~A}$ and S3A). NCAPH2 had lower transcript expression in $\mathrm{HPV}^{\mathrm{U}}$ tumors in both patient cohorts and CTCF and RICTOR had lower transcript expression in $\mathrm{HPV}^{\mathrm{U}}$ tumors from the NOR-TCGA set (Figures 3B and S3B). Furthermore, genes found to be differentially expressed between $\mathrm{HPV}^{\mathrm{U}}$ and $\mathrm{HPV}^{+}$tumors in the WUSM patient cohort were enriched in hallmark E2F targets (FDR $<0.001)$ and G2M checkpoint pathways (FDR $=0.002347$ ) (Figure S3C-E).

\section{A}

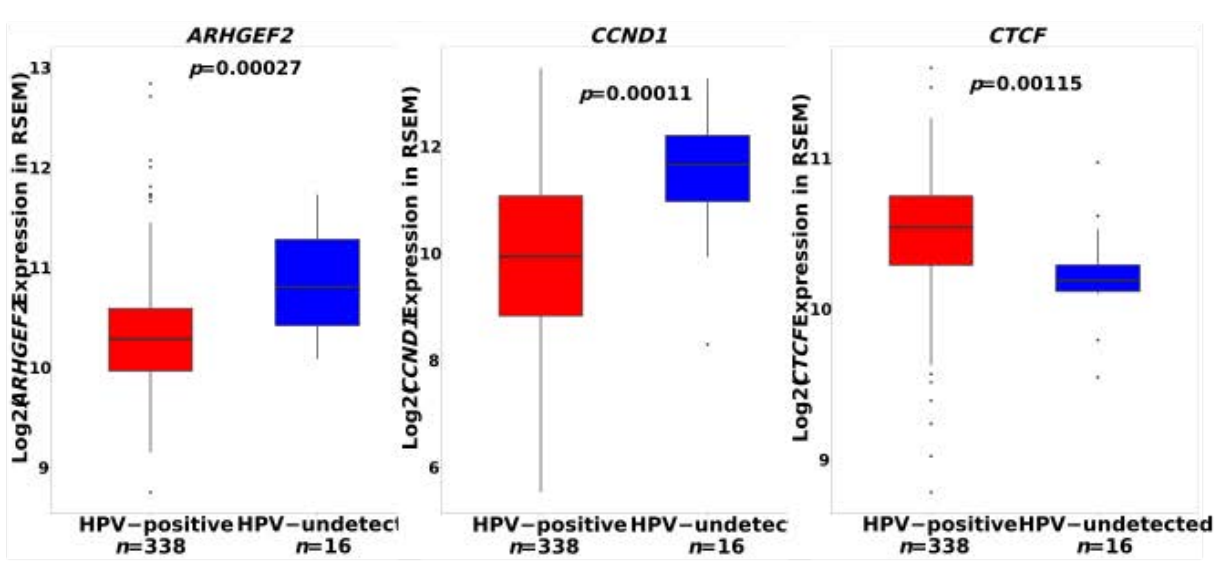

B

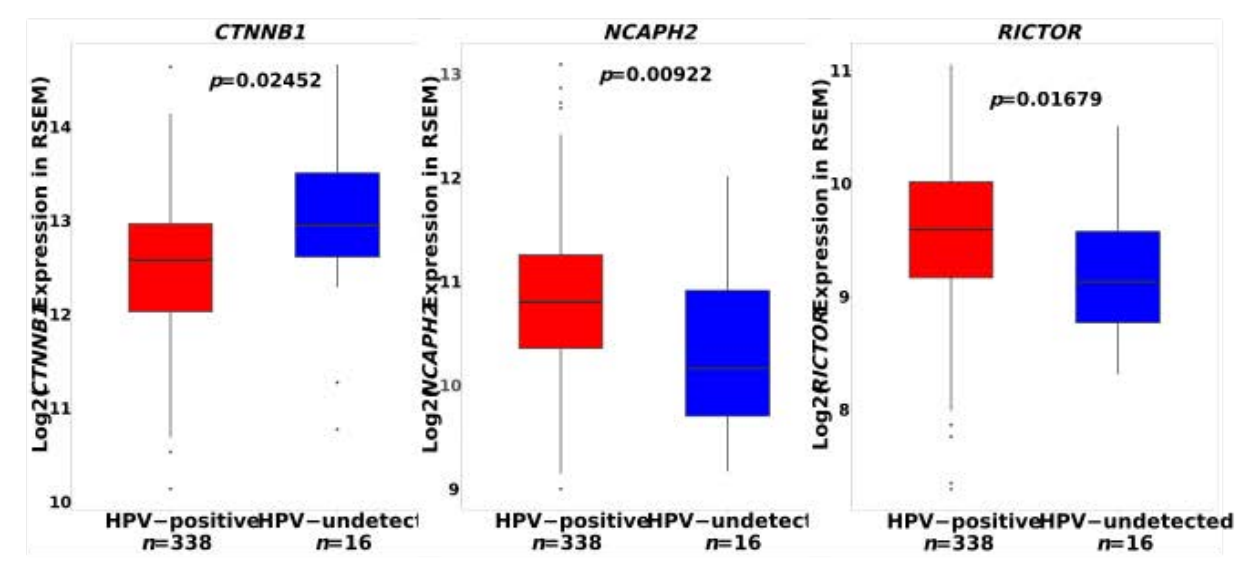

Figure 3. SMGs up- and downregulated in $\mathrm{HPV}^{\mathrm{U}}$ tumors. (A) $\mathrm{SMGs}$ in $\mathrm{HPV}^{\mathrm{U}}$ tumors from the NOR-TCGA patient set that are upregulated and (B) down regulated. Mann-Whitney-Wilcoxon $p$ values shown.

\subsection{Identification of a Clinically Actionable Target in $\mathrm{HPV}^{U} \mathrm{CC}$}

All seven SMGs identified in the NOR-TCGA and WUSM combined genomic analysis have converging biological roles in coordinating G1 to S phase cell cycle progression, shown in Figure 4. Additionally, $\mathrm{HPV}^{\mathrm{U}}$ tumors had higher CCND1 transcript expression in both the NOR-TCGA and WUSM cohorts, and CCND1 was present in a significant 11q13.3 amplification peak in the NOR-TCGA set. In $\mathrm{HPV}^{+}$cervical cancer, expression of HPV E7 drives bypass of the $\mathrm{G} 1$ cell cycle checkpoint by targeting $\mathrm{Rb}$ for proteasomal degradation. Since HPV ${ }^{\mathrm{U}}$ cervical cancers may bypass the G1 checkpoint via a different mechanism than $\mathrm{HPV}^{+}$tumors, we hypothesize that $\mathrm{HPV}^{\mathrm{U}}$ tumors may be more sensitive than $\mathrm{HPV}^{+}$ tumors to the FDA approved CDK 4/6 inhibitor palbociclib (Graphical Abstract). 
A

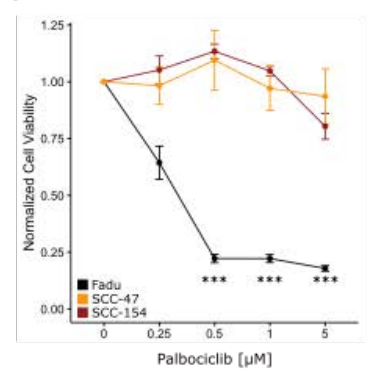

C

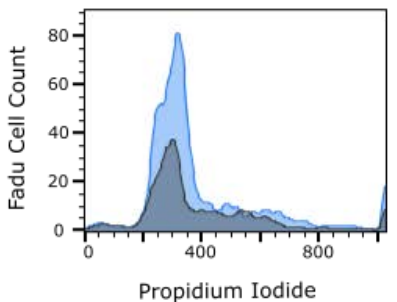

D

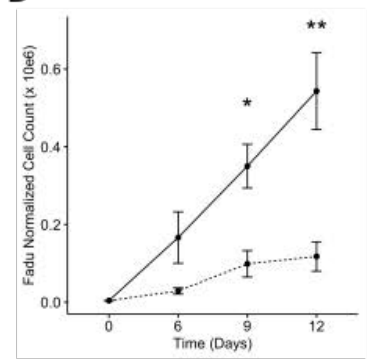

B

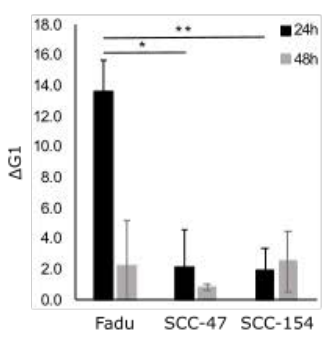

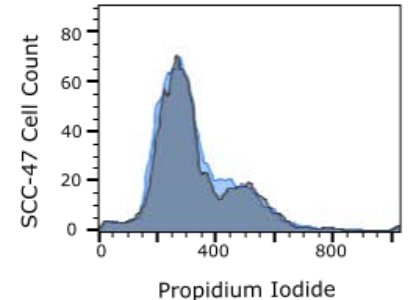

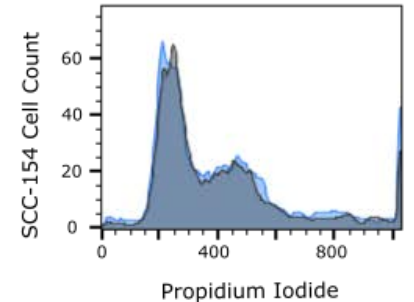

Propidium Iodide
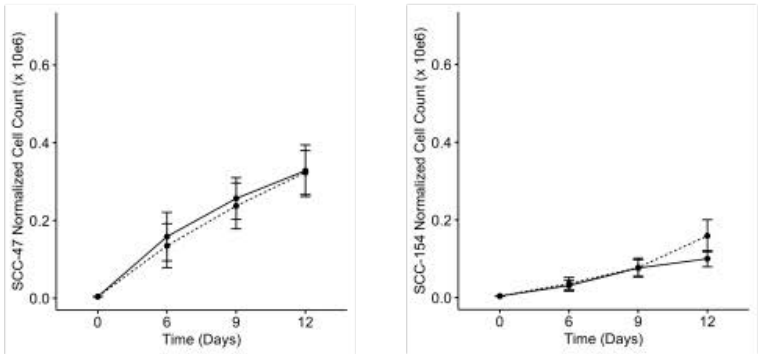

$E$

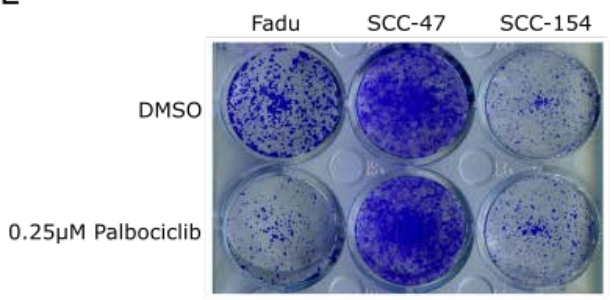

Figure 4. HNSCC cell line sensitivity to Palbociclib. (A) Cell viability by alamar blue was evaluated 5 days after Palbociclib treatment alone (Student's $t$-test, ${ }^{*} p<0.05$, ${ }^{* * *} p<0.001$ ). (B) Average increase in G1 cell cycle arrest 24 (black) and $48 \mathrm{~h}$ (grey) after $0.25 \mu \mathrm{M}$ Palbociclib treatment (Avg $\pm \mathrm{SEM}$, student's $t$-test, * $p<0.05,{ }^{* *} p<0.01$ ). (C) Representative histograms of HPV negative Fadu and HPV positive SCC-47 and SCC-154 (grey = vehicle, blue $=0.25 \mu \mathrm{M}$ Palbociclib). (D,E) Cells were counted at 6-, 9-, and 12-days post-Palbociclib treatment and (D) proliferation curves after Palbociclib treatment were made (solid $=$ vehicle and dashed $=0.25 \mu \mathrm{M}$ Palbociclib; Wilcoxon test ${ }^{*} p<0.05$, ** $p<0.01$ ). (E) Representative crystal violet stained day 12 plate.

\subsection{HPV U Cell Lines with Intact RB1 Are Selectively Sensitivity to CDK4/6 Inhibition}

Palbociclib restores $\mathrm{G} 1$ cell cycle arrest through inhibition of CDK4/ 6 which attenuates cyclin D1's ability to phosphorylate and inhibit $\mathrm{Rb}$. HPV $\mathrm{H}^{\mathrm{U}}$ cervical cancer cell lines $\mathrm{C} 33 \mathrm{~A}$ and HT3 were tested for sensitivity to palbociclib monotherapy alongside the $\mathrm{HPV}^{+} \mathrm{SiHa}$ and Caski cervical cancer cell lines. We did not observe any sensitivity of either the HPV or $\mathrm{HPV}^{+}$cell lines to palbociclib (Table S4). Previous groups have established that wildtype (WT) Rb is necessary for palbociclib to be effective, with palbociclib having no effect on proliferation in $\mathrm{Rb}$ deficient cell lines even under concentrations more than 50 times 
greater than that needed for efficacy in $\mathrm{Rb}$ proficient cells [23]. Although we did not detect any $R B 1$ mutations in our $\mathrm{HPV}^{\mathrm{U}}$ cervical tumor specimens, both $\mathrm{HPV}^{\mathrm{U}}$ cervical cancer cell lines C33A and HT3 were found to harbor RB1 mutations according to the COSMIC cell lines database [24] (Figures 4 and S4A). Therefore, in order to evaluate the efficacy of palbociclib treatment in $\mathrm{HPV}^{\mathrm{U}}$ versus $\mathrm{HPV}^{+}$cell lines we evaluated a panel of head and neck squamous cell carcinoma (HNSCC) cell lines. The HPV ${ }^{\mathrm{U}}$ Fadu and HPV 16 positive SCC-47 and SCC-154 HNSCC cell lines all are RB1 WT, and the Fadu cell line overexpressed cyclin D1 (Figure S4B).

$\mathrm{HPV}^{\mathrm{U}}$ Fadu cells were sensitive to all doses of palbociclib tested $(0.25 \mu \mathrm{M}, p<0.05$; $0.5-5 \mu \mathrm{M}, p<0.001$ ) (Figure 4A). Palbociclib had no effect on the $\mathrm{HPV}^{+}$cell line's viability (Figure 4A). We treated our HNSCC cell line panel with palbociclib $1 \mathrm{~h}$ prior to radiation treatment and assessed cell viability five days after treatment; we did not see any significant radiosensitization by palbociclib treatment in any of the cell lines tested irrespective of HPV status (Figure S4C).

\subsection{CDK4/6 Inhibition Induces G1 Arrest and Decreased Proliferation in HPV ${ }^{U}$ Cell Lines}

The effect of palbociclib on G1 cell cycle arrest was evaluated by treating cells with vehicle $(0.01 \%$ DMSO) or $0.25 \mu \mathrm{M}$ palbociclib and harvesting them 24 and $48 \mathrm{~h}$ after treatment. G1 cell cycle arrest was maximal $24 \mathrm{~h}$ after palbociclib treatment, with an average increase in $\mathrm{G} 1$ cells, across three independent replicates, of $13.6 \%, 2.2 \%$, and $2.0 \%$ for Fadu, SCC-47 and SCC-154 cells respectively (Figure 4B,C). Fadu cells treated with palbociclib had attenuated growth rates compared to vehicle treated controls ( $99, p<0.05$; D12, $p<0.01$ ), while HPV ${ }^{+}$SCC-47 and SCC-154 showed no delays in growth rate after treatment with palbociclib (Figure 4D,E).

\section{Discussion}

Various methodologies are used to detect HPV in patient tumors, however there is currently no universal consensus on defining $\mathrm{HPV}^{\mathrm{U}} \mathrm{CC}$. The most prevalent clinical test for HPV is the use of immunohistochemical (IHC) staining of primary tumor biopsies for p16. Although p16 IHC is reproducible and easy to perform in the clinical laboratory setting, p16 expression can occur independently of HPV infection, and may overestimate the number of tumors assumed to be $\mathrm{HPV}^{+}[25,26]$. Since HPV status is associated with patient survival, it is imperative to correctly identify patients with $\mathrm{HPV}^{\mathrm{U}}$ tumors. In the research setting the current gold standard of HPV testing is RNAseq based detection of HPV viral transcripts $[15,17]$. Using RNAseq data, researchers align the sequence reads to reference genomes for all HPV genotypes thereby decreasing the amount of false negative calls. However, the threshold of viral transcript expression necessary to define an $\mathrm{HPV}^{+}$ tumor varies between research groups. For HNSCC, the TCGA definition of HPV negativity was less than $1000 \mathrm{HPV}$ transcript reads per tumor sample [27]. The TCGA cervix cancer standard for defining HPV negativity was any tumors with less than $1 \mathrm{HPV}$ read per million (RPM) human reads [15]. Future work will need to be done to clarify what threshold of HPV detection is biologically meaningful.

Apart from the limits of detection, it has also been postulated that $\mathrm{HPV}^{\mathrm{U}}$ tumors may result from the loss of HPV nucleic acids as the tumors become larger and more advanced [13]. Although our study does not rule out this hypothesis, we did not observe any association between tumor stage and $\mathrm{HPV}^{\mathrm{U}}$ status, suggesting there may be other potential explanations. While the association between HPV infection and cervical cancer is incontestable, there is no evidence to suggest that the cervix is uniquely protected from the non-HPV-related carcinogenic processes that occur in other tissues of the body. In addition, one would intuitively expect that HPV-driven cervical cancer will more likely be diagnosed earlier rather than later in life if HPV detection and treatment are not done at the precancerous stage. Therefore, our confirmation of an association between $\mathrm{HPV}^{\mathrm{U}}$ tumors and older age of diagnosis supports the possibility that at least some $\mathrm{HPV}^{\mathrm{U}}$ tumors may indeed not be driven by HPV infection [13]. 
Similar to previous studies, we identified TP53, PTEN, ARID1A, ARID5B, and CTNNB1 as SMGs in HPV ${ }^{\mathrm{U}}$ tumors [14]. Although these findings are strikingly similar to the SMG profile in endometrial carcinomas [28], multiple rounds of histopathological investigations (both published and unpublished) indicate that these tumors were indeed of cervical origin $[15,17]$. Notably, our novel identification of CCND1 and CTCF as SMGs put the converging role of cell cycle progression in $\mathrm{HPV}^{\mathrm{U}}$ cervical cancer into clear perspective. In particular, the contribution of CCND1 was highlighted both by activating P287T mutations and copy number amplifications [29]. It is not surprising to observe that $50 \%$ of $\mathrm{HPV}^{\mathrm{U}}$ tumors harbor TP53 mutations given the role of the HPV E6 oncogene in abrogating p53 function. It is also intriguing that several novel $\mathrm{HPV}^{\mathrm{U}}$ associated SMGs have direct and indirect links to HPV biology, suggesting that the effect of the somatic mutations in the absence of HPV may be similar to the synergy between the wild type forms and HPV in cancer. For example, KIAA1012 encodes TRAPPC8, a transport protein essential for successful HPV cellular entry [30]. The E2 open reading frame of high-risk HPVs possesses a conserved CTCF binding site. Loss of CTCF binding via mutation of the CTCF binding site increases E6 and E7 viral expression with concomitant increase in cellular proliferation [31]. It is tempting to speculate that somatic mutations in human CTCF in the absence of HPV may mimic HPV-CTCF interactions and influence tumorigenesis.

The identification of RICTOR as an SMG mutation suggests that it may be an oncogene in the context of $\mathrm{HPV}^{\mathrm{U}}$ tumors with the possibility for therapy with mTORC2 inhibitors. The relatively low expression of RICTOR in HPV ${ }^{\mathrm{U}}$ tumors is therefore puzzling but may be explained in part by an indirect effect of HPV E6 on RICTOR expression. RICTOR is a target of mir-218 [32], which in turn is known to be suppressed by HPV E6 [33]. Therefore, in the absence of HPV, RICTOR expression may be downregulated. Interestingly, a tumor suppressive function has recently been demonstrated for RICTOR in p53-mutant medulloblastoma [34]. Some genes in copy number deletion peaks have either known tumor suppressor functions or biological features that support a suppressive role in tumorigenesis. For example, RNF111 encodes the Arkadia protein which has been shown to enhance tumor suppression in colorectal, renal cell, and lung carcinoma by enhancing TGF-beta signaling [35-37], while PPWD1 encodes a peptidylprolyl isomerase which contains WD40 domains and is thought to play a role in protein folding and pre-mRNA splicing [38,39].

Although our study's primary focus was in the identification of coding genes differentially mutated and/or expressed in $\mathrm{HPV}^{\mathrm{U}}$ compared to $\mathrm{HPV}^{+} \mathrm{CC}$ that contribute to treatment resistance, there is also increasing evidence that micro- and long non-coding RNAs also contribute to disease resistance. One such study found that mir-21 and mir-155 were more highly expressed in CC tumors as compared to normal cervix tissue [40]. Additionally, the study found that the expression of these micro-RNAs differed between $\mathrm{HPV}^{+}$ and $\mathrm{HPV}^{-} \mathrm{CC}$ tumors, however regardless of HPV status both mir-21 and mir-155 were shown to be a significant predictive indicator of cervical cancer. The authors postulated that the expression of these micro-RNAs may be of high diagnostic value as they have the ability to help predict and identify both $\mathrm{HPV}^{+}$and $\mathrm{HPV}^{-} \mathrm{CC}$ development.

In this study, we are the first to show that $\mathrm{HPV}^{\mathrm{U}} \mathrm{CC}$ tumors harbor mutations and alterations in transcriptional regulation to overcome G1 cell cycle arrest. We identified mutations and/or overexpression of $\beta$-catenin and cyclin D1 which binds to CDK4/6 and inhibits $\mathrm{Rb}$ and allows cell cycle progression. The FDA approved CDK4/6 inhibitor, palbociclib was evaluated for efficacy as a single agent therapeutic in $\mathrm{HPV}^{\mathrm{U}}$ and $\mathrm{HPV}^{+}$ HNSCC cell lines. In response to single agent palbociclib treatment the HPV ${ }^{\mathrm{U}}$ Fadu cell line exhibited increased G1 cell cycle arrest $24 \mathrm{~h}$ after treatment, prolonged proliferation attenuation up to 12 days after treatment and decreased cell viability compared to untreated controls. The HPV ${ }^{+}$SCC-47 and SCC-154 cells showed no significant effects on G1 cell cycle arrest, proliferation rate or cell viability after palbociclib treatment.

A caveat of our present study was that we were unable to assess palbociclib sensitivity using $\mathrm{HPV}^{\mathrm{U}}$ cervical cancer cell lines due to the C33A and HT3 cell lines harboring RB1 mutations [24], and palbocilib sensitivity has been previously reported to be dependent on 
intact RB1 signaling. However, our findings using HNSCC cell lines have been corroborated by two recent studies showing that the cervical $\mathrm{HPV}^{\mathrm{U}}$ cell line $\mathrm{C} 33 \mathrm{~A}$ is preferentially sensitive to cyclin D1 inhibitors [41,42]. Of note, $R B 1$ is not frequently mutated in either $\mathrm{HPV}^{\mathrm{U}}$ or $\mathrm{HPV}^{+} \mathrm{CC}$ patients from either NOR-TCGA or WUSM cohorts. Additionally, RB1 mutations have not been identified as frequently mutated in cervix cancer cohorts from other independent studies $[15,17]$. Therefore, this treatment strategy should still be considered as a viable option for patients with $\mathrm{HPV}^{\mathrm{U}} \mathrm{CC}$ with wild type RB1. Lastly, a recent publication found palbociclib was able to sensitize $\mathrm{HPV}^{\mathrm{U}}$ but not $\mathrm{HPV}^{+} \mathrm{HNSCC}$ cell lines to radiation treatment [43]. However, in our study, we did not find any radiosensitization when combining palbociclib with radiation treatment. One reason for this discrepancy may be the difference in endpoints used. In our study we used the Alamar Blue cell viability as our endpoint for cell survival, whereas Göttgens et al. used clonogenic potential. It may be that the combination of palbociclib and radiation treatment acts as a cytostatic therapy, preferentially targeting $\mathrm{HPV}^{\mathrm{U}}$ cancer cells and attenuating their ability to actively engage their cell cycle. Therefore, although combination treatment does not synergize to decrease cell viability, this strategy may be effective to attenuate $\mathrm{HPV}^{\mathrm{U}}$ cancer cells ability to proliferate. Altogether the results from our study indicate that $\mathrm{HPV}^{\mathrm{U}}$ cell lines are uniquely responsive to single agent palbociclib treatment and set the stage for clinical testing to determine if patients with $\mathrm{HPV}^{\mathrm{U}}$ cervical carcinomas could benefit from the addition of palbociclib into their treatment plan.

\section{Conclusions}

HPV status has the potential to be a powerful prognostic biomarker of CC patient progression-free and overall survival. In this multi-institutional study, we have identified and validated $\mathrm{HPV}^{\mathrm{U}}$ as a poor prognostic marker in cervical cancer. Patients with $\mathrm{HPV}^{\mathrm{U}}$ cervical tumors had higher recurrence and mortality rates after surgery and standard of care CRT treatment compared to patients with $\mathrm{HPV}^{+}$tumors (Figure 1). In current clinical practice, routine HPV testing is only performed on precancerous cervical lesions; however, our results highlight the need for routine HPV testing of primary cervix tumors in order to identify patients that have $\mathrm{HPV}^{\mathrm{U}}$ tumors prior to the initiation of treatment. These patients are likely to fail their standard of care treatment and may benefit from alternative treatment plans, which could include radiation or chemotherapy dose escalation, including the addition of biologically targeted agents. In this study, using the largest cohort of HPV cervical cancers reported to date, we have performed detailed biological characterization which has identified cell cycle regulation as a rational target for $\mathrm{HPV}^{\mathrm{U}}$ tumors, and, using a panel $\mathrm{HPV}^{+}$and $\mathrm{HPV}^{\mathrm{U}}$ cell lines, we have shown that the CDK4/ 6 inhibitor palbociclib is a potential alternative treatment strategy.

Supplementary Materials: The following are available online at https: / www.mdpi.com/article/ 10.3390/ cancers13184551/s1, Table S1: Clinical characteristics of patient cohorts; Table S2: Targeted Gene Panel for WUSM cohort sequencing; Table S3: MutSig2CV SMG list and co-occurrence/mutual exclusivity of SMGs in HPV ${ }^{U}$ tumors; Supplementary Table S4: HPV status, RB and TP53 mutational profile across cell lines; Figure S1: Somatic copy number alterations (SCNAs) in HPV tumors; Figure S2: Similarity matrix for presence/absence of mutations and SCNAs in HPV ${ }^{U}$ tumors; Figure S3: WUSM SMG transcript expression and DE analysis; Figure S4: CESC and HNSCC cell line sensitivity to Palbociclib mono-therapy and combination with RT.

Author Contributions: F.J.R.: Conceptualization, Methodology, Formal analysis, Investigation, Visualization, Validation, Writing-Original Draft, Writing-Review and Editing. A.S.: Formal analysis, Visualization, Validation. J.Z. (Jin Zhang): Formal analysis. C.S.P.: Formal analysis, Data Curation. M.K.H.: Resources and Data Curation Norwegian cohort. V.S.: Formal analysis, Data Curation. J.Z. (Jianqing Zhang): Formal analysis. N.M.: Investigation. J.S.: Investigation. S.M.: Resources and Data Curation WUSM cohort. H.K.T.: Formal analysis, Data Curation. Resources and Data Curation WUSM Cohort. P.W.G.: Resources and Data Curation WUSM cohort. C.K.: Resources and Data Curation Norwegian Cohort. J.K.S.: Conceptualization, Methodology, Resources and Data Curation WUSM cohort, Writing-Original Draft, Writing-Review and Editing, Supervision. A.I.O.: 
Conceptualization, Methodology, Formal Analysis, Visualization, Validation, Resources and Data Curation Norwegian cohort, Writing-Original Draft, Writing-Review and Editing, Supervision. All authors have read and agreed to the published version of the manuscript.

Funding: This work was supported in part by NIH R01CA181745 (J.K.S.), NCI U54CA118948 Career Development Supplement, the Endlichhofer Trust and V Foundation grants V2015-009 and DVP2018007 (A.I.O.), NIH T32 CA113275 (F.J.R.), NIH K08CA237822 (S.M.), NCI K22CA237839 (Jin Zhang), Norwegian Research Council grant no. 273280 (C.K.), and HelseVest grant no. 912227 (M.K.H.).

Institutional Review Board Statement: All patients gave written informed consent, and the study was approved by the regional health committee for both NOR (REK 2018/591 and 2014/1907) and WUSM (no. 201105374) cohort patients.

Informed Consent Statement: Informed consent was obtained from all subjects involved in the study.

Data Availability Statement: NOR-TCGA cohort data archived in dbGaP which were originally derived from two published sources: Ojesina et al. [17], and the Cancer Genome Atlas Network (TCGA) [15] (accession numbers phs000600.v1.p1 and phs000178.v11.p8, respectively). WUSM cohort RNAseq data can be accessed at Gene Expression Omnibus (GEO) with accession number GSE151666.

Conflicts of Interest: The authors declare no conflict of interest.

\section{References}

1. Bray, F.; Ferlay, J.; Soerjomataram, I.; Siegel, R.L.; Torre, L.A.; Jemal, A. Global Cancer Statistics 2018: GLOBOCAN Estimates of Incidence and Mortality Worldwide for 36 Cancers in 185 Countries. CA. Cancer J. Clin. 2018, 68, 394-424. [CrossRef] [PubMed]

2. Saraiya, M.; Unger, E.R.; Thompson, T.D.; Lynch, C.F.; Hernandez, B.Y.; Lyu, C.W.; Steinau, M.; Watson, M.; Wilkinson, E.J.; Hopenhayn, C.; et al. US Assessment of HPV Types in Cancers: Implications for Current and 9-Valent HPV Vaccines. J. Natl. Cancer Inst. 2015, 107, djv086. [CrossRef] [PubMed]

3. Reimers, N.; Kasper, H.U.; Weissenborn, S.J.; Stützer, H.; Preuss, S.F.; Hoffmann, T.K.; Speel, E.J.M.; Dienes, H.P.; Pfister, H.J.; Guntinas-Lichius, O.; et al. Combined Analysis of HPV-DNA, P16 and EGFR Expression to Predict Prognosis in Oropharyngeal Cancer. Int. J. Cancer 2007, 120, 1731-1738. [CrossRef] [PubMed]

4. Fakhry, C.; Lacchetti, C.; Rooper, L.M.; Jordan, R.C.; Rischin, D.; Sturgis, E.M.; Bell, D.; Lingen, M.W.; Harichand-Herdt, S.; Thibo, J.; et al. Human Papillomavirus Testing in Head and Neck Carcinomas: ASCO Clinical Practice Guideline Endorsement of the College of American Pathologists Guideline. J. Clin. Oncol. 2018, 36, 3152-3161. [CrossRef]

5. Smith, E.M.; Wang, D.; Kim, Y.; Rubenstein, L.M.; Lee, J.H.; Haugen, T.H.; Turek, L.P. P16INK4a Expression, Human Papillomavirus, and Survival in Head and Neck Cancer. Oral Oncol. 2008, 44, 133-142. [CrossRef]

6. Dayyani, F.; Etzel, C.J.; Liu, M.; Ho, C.-H.; Lippman, S.M.; Tsao, A.S. Meta-Analysis of the Impact of Human Papillomavirus (HPV) on Cancer Risk and Overall Survival in Head and Neck Squamous Cell Carcinomas (HNSCC). Head Neck Oncol. 2010, 2, 15. [CrossRef]

7. Harima, Y.; Sawada, S.; Nagata, K.; Sougawa, M.; Ohnishi, T. Human Papilloma Virus (HPV) DNA Associated with Prognosis of Cervical Cancer after Radiotherapy. Int. J. Radiat. Oncol. 2002, 52, 1345-1351. [CrossRef]

8. Lindel, K.; Burri, P.; Studer, H.U.; Altermatt, H.J.; Greiner, R.H.; Gruber, G. Human Papillomavirus Status in Advanced Cervical Cancer: Predictive and Prognostic Significance for Curative Radiation Treatment. Int. J. Gynecol. Cancer 2005, 15, $278-284$. [CrossRef]

9. Rodríguez-Carunchio, L.; Soveral, I.; Steenbergen, R.D.M.; Torné, A.; Martinez, S.; Fusté, P.; Pahisa, J.; Marimon, L.; Ordi, J.; del Pino, M. HPV-Negative Carcinoma of the Uterine Cervix: A Distinct Type of Cervical Cancer with Poor Prognosis. BJOG Int. J. Obstet. Gynaecol. 2015, 122, 119-127. [CrossRef]

10. Okuma, K.; Yamashita, H.; Yokoyama, T.; Nakagawa, K.; Kawana, K. Undetected Human Papillomavirus DNA and Uterine Cervical Carcinoma. Strahlenther. Onkol. 2016, 192, 55-62. [CrossRef]

11. Li, P.; Tan, Y.; Zhu, L.-X.; Zhou, L.-N.; Zeng, P.; Liu, Q.; Chen, M.-B.; Tian, Y. Prognostic Value of HPV DNA Status in Cervical Cancer before Treatment: A Systematic Review and Meta-Analysis. Oncotarget 2017, 8, 66352-66359. [CrossRef]

12. Jeronimo, J.; Castle, P.E.; Temin, S.; Denny, L.; Gupta, V.; Kim, J.J.; Luciani, S.; Murokora, D.; Ngoma, T.; Qiao, Y.; et al. Secondary Prevention of Cervical Cancer: ASCO Resource-Stratified Clinical Practice Guideline. J. Glob. Oncol. 2016, 3, 635-657. [CrossRef]

13. Uchiyama, M.; Iwasaka, T.; Matsuo, N.; Hachisuga, T.; Mori, M.; Sugimori, H. Correlation between Human Papillomavirus Positivity and P53 Gene Overexpression in Adenocarcinoma of the Uterine Cervix. Gynecol. Oncol. 1997, 65, 23-29. [CrossRef]

14. Banister, C.E.; Liu, C.; Pirisi, L.; Creek, K.E.; Buckhaults, P.J. Identification and Characterization of HPV-Independent Cervical Cancers. Oncotarget 2017, 8, 13375-13386. [CrossRef]

15. The Cancer Genome Atlas Research Network. Integrated Genomic and Molecular Characterization of Cervical Cancer. Nature 2017, 543, 378-384. [CrossRef]

16. Chong, G.O.; Lee, Y.H.; Han, H.S.; Lee, H.J.; Park, J.Y.; Hong, D.G.; Lee, Y.S.; Cho, Y.L. Prognostic Value of Pre-Treatment Human Papilloma Virus DNA Status in Cervical Cancer. Gynecol. Oncol. 2018, 148, 97-102. [CrossRef] 
17. Ojesina, A.I.; Lichtenstein, L.; Freeman, S.S.; Pedamallu, C.S.; Imaz-Rosshandler, I.; Pugh, T.J.; Cherniack, A.D.; Ambrogio, L.; Cibulskis, K.; Bertelsen, B.; et al. Landscape of Genomic Alterations in Cervical Carcinomas. Nature 2014, 506, 371-375. [CrossRef]

18. Kandoth, C.; McLellan, M.D.; Vandin, F.; Ye, K.; Niu, B.; Lu, C.; Xie, M.; Zhang, Q.; McMichael, J.F.; Wyczalkowski, M.A.; et al. Mutational Landscape and Significance across 12 Major Cancer Types. Nature 2013, 502, 333-339. [CrossRef]

19. Kostic, A.D.; Ojesina, A.I.; Pedamallu, C.S.; Jung, J.; Verhaak, R.G.W.; Getz, G.; Meyerson, M. PathSeq: Software to Identify or Discover Microbes by Deep Sequencing of Human Tissue. Nat. Biotechnol. 2011, 29, 393-396. [CrossRef]

20. Cibulskis, K.; Lawrence, M.S.; Carter, S.L.; Sivachenko, A.; Jaffe, D.; Sougnez, C.; Gabriel, S.; Meyerson, M.; Lander, E.S.; Getz, G. Sensitive Detection of Somatic Point Mutations in Impure and Heterogeneous Cancer Samples. Nat. Biotechnol. 2013, 31, $213-219$. [CrossRef]

21. Lawrence, M.S.; Stojanov, P.; Polak, P.; Kryukov, G.V.; Cibulskis, K.; Sivachenko, A.; Carter, S.L.; Stewart, C.; Mermel, C.H.; Roberts, S.A.; et al. Mutational Heterogeneity in Cancer and the Search for New Cancer-Associated Genes. Nature 2013, 499, 214-218. [CrossRef]

22. Mermel, C.H.; Schumacher, S.E.; Hill, B.; Meyerson, M.L.; Beroukhim, R.; Getz, G. GISTIC2.0 Facilitates Sensitive and Confident Localization of the Targets of Focal Somatic Copy-Number Alteration in Human Cancers. Genome Biol. 2011, 12, R41. [CrossRef]

23. Fry, D.W.; Harvey, P.J.; Keller, P.R.; Elliott, W.L.; Meade, M.; Trachet, E.; Albassam, M.; Zheng, X.; Leopold, W.R.; Pryer, N.K.; et al. Specific Inhibition of Cyclin-Dependent Kinase 4/ 6 by PD 0332991 and Associated Antitumor Activity in Human Tumor Xenografts. Mol. Cancer Ther. 2004, 3, 1427-1438.

24. Cosmic COSMIC -Catalogue of Somatic Mutations in Cancer. Available online: https://cancer.sanger.ac.uk/cell_lines (accessed on 4 November 2019).

25. Schlecht, N.F.; Brandwein-Gensler, M.; Nuovo, G.J.; Li, M.; Dunne, A.; Kawachi, N.; Smith, R.V.; Burk, R.D.; Prystowsky, M.B. A Comparison of Clinically Utilized Human Papillomavirus Detection Methods in Head and Neck Cancer. Mod. Pathol. 2011, 24, 1295-1305. [CrossRef]

26. Götz, C.; Drecoll, E.; Straub, M.; Bissinger, O.; Wolff, K.-D.; Kolk, A. Impact of HPV Infection on Oral Squamous Cell Carcinoma. Oncotarget 2016, 7, 76704-76712. [CrossRef]

27. The Cancer Genome Atlas Network. Comprehensive Genomic Characterization of Head and Neck Squamous Cell Carcinomas. Nature 2015, 517, 576-582. [CrossRef]

28. Cancer Genome Atlas Research Network; Kandoth, C.; Schultz, N.; Cherniack, A.D.; Akbani, R.; Liu, Y.; Shen, H.; Robertson, A.G.; Pashtan, I.; Shen, R.; et al. Integrated Genomic Characterization of Endometrial Carcinoma. Nature 2013, 497, 67-73. [CrossRef]

29. Moreno-Bueno, G.; Rodríguez-Perales, S.; Sánchez-Estévez, C.; Hardisson, D.; Sarrió, D.; Prat, J.; Cigudosa, J.C.; Matias-Guiu, X.; Palacios, J. Cyclin D1 Gene (CCND1) Mutations in Endometrial Cancer. Oncogene 2003, 22, 6115-6118. [CrossRef] [PubMed]

30. Ishii, Y.; Nakahara, T.; Kataoka, M.; Kusumoto-Matsuo, R.; Mori, S.; Takeuchi, T.; Kukimoto, I. Identification of TRAPPC8 as a Host Factor Required for Human Papillomavirus Cell Entry. PLoS ONE 2013, 8, e80297. [CrossRef]

31. Paris, C.; Pentland, I.; Groves, I.; Roberts, D.C.; Powis, S.J.; Coleman, N.; Roberts, S.; Parish, J.L. CCCTC-Binding Factor Recruitment to the Early Region of the Human Papillomavirus 18 Genome Regulates Viral Oncogene Expression. J. Virol. 2015, 89, 4770-4785. [CrossRef] [PubMed]

32. Uesugi, A.; Kozaki, K.-I.; Tsuruta, T.; Furuta, M.; Morita, K.-I.; Imoto, I.; Omura, K.; Inazawa, J. The Tumor Suppressive MicroRNA MiR-218 Targets the MTOR Component Rictor and Inhibits AKT Phosphorylation in Oral Cancer. Cancer Res. 2011, 71, 5765-5778. [CrossRef] [PubMed]

33. Martinez, I.; Gardiner, A.S.; Board, K.F.; Monzon, F.A.; Edwards, R.P.; Khan, S.A. Human Papillomavirus Type 16 Reduces the Expression of MicroRNA-218 in Cervical Carcinoma Cells. Oncogene 2008, 27, 2575-2582. [CrossRef]

34. Akgül, S.; Li, Y.; Zheng, S.; Kool, M.; Treisman, D.M.; Li, C.; Wang, Y.; Gröbner, S.; Ikenoue, T.; Shen, Y.; et al. Opposing TumorPromoting and -Suppressive Functions of Rictor/MTORC2 Signaling in Adult Glioma and Pediatric SHH Medulloblastoma. Cell Rep. 2018, 24, 463-478.e5. [CrossRef] [PubMed]

35. Mizutani, A.; Koinuma, D.; Seimiya, H.; Miyazono, K. The Arkadia-ESRP2 Axis Suppresses Tumor Progression: Analyses in Clear-Cell Renal Cell Carcinoma. Oncogene 2016, 35, 3514-3523. [CrossRef]

36. Sharma, V.; Antonacopoulou, A.G.; Tanaka, S.; Panoutsopoulos, A.A.; Bravou, V.; Kalofonos, H.P.; Episkopou, V. Enhancement of TGF- $\beta$ Signaling Responses by the E3 Ubiquitin Ligase Arkadia Provides Tumor Suppression in Colorectal Cancer. Cancer Res. 2011, 71, 6438-6449. [CrossRef]

37. Briones-Orta, M.A.; Levy, L.; Madsen, C.D.; Das, D.; Erker, Y.; Sahai, E.; Hill, C.S. Arkadia Regulates Tumor Metastasis by Modulation of the TGF- $\beta$ Pathway. Cancer Res. 2013, 73, 1800-1810. [CrossRef]

38. Davis, T.L.; Walker, J.R.; Campagna-Slater, V.; Finerty, P.J.; Paramanathan, R.; Bernstein, G.; MacKenzie, F.; Tempel, W.; Ouyang, H.; Lee, W.H.; et al. Structural and Biochemical Characterization of the Human Cyclophilin Family of Peptidyl-Prolyl Isomerases. PLoS Biol. 2010, 8, e1000439. [CrossRef]

39. Jurica, M.S.; Licklider, L.J.; Gygi, S.R.; Grigorieff, N.; Moore, M.J. Purification and Characterization of Native Spliceosomes Suitable for Three-Dimensional Structural Analysis. RNA 2002, 8, 426-439. [CrossRef]

40. Park, S.; Eom, K.; Kim, J.; Bang, H.; Wang, H.; Ahn, S.; Kim, G.; Jang, H.; Kim, S.; Lee, D.; et al. MiR-9, MiR-21, and MiR-155 as Potential Biomarkers for HPV Positive and Negative Cervical Cancer. BMC Cancer 2017, 17, 658. [CrossRef] 
41. Kennedy, A.L.; Rai, R.; Isingizwe, Z.R.; Zhao, Y.D.; Lightfoot, S.A.; Benbrook, D.M. Complementary Targeting of Rb Phosphorylation and Growth in Cervical Cancer Cell Cultures and a Xenograft Mouse Model by SHetA2 and Palbociclib. Cancers 2020, 12, 1269. [CrossRef]

42. Xiong, Y.; Li, T.; Assani, G.; Ling, H.; Zhou, Q.; Zeng, Y.; Zhou, F.; Zhou, Y. Ribociclib, a Selective Cyclin D Kinase $4 / 6$ Inhibitor, Inhibits Proliferation and Induces Apoptosis of Human Cervical Cancer in Vitro and in Vivo. Biomed. Pharmacother. Biomed. Pharmacother. 2019, 112, 108602. [CrossRef]

43. Göttgens, E.-L.; Bussink, J.; Leszczynska, K.B.; Peters, H.; Span, P.N.; Hammond, E.M. Inhibition of CDK4/CDK6 Enhances Radiosensitivity of HPV Negative Head and Neck Squamous Cell Carcinomas. Int. J. Radiat. Oncol. 2019, 105, 548-558. [CrossRef] 